\title{
Tradição, tradução, transparências
}

\author{
João de Jesus Paes Loureiro*
}

Resumo: O autor vale-se do conceito da estética do vitral para, em linguagem alegórica, compreender o fenômeno cultural na Amazônia, cujas manifestações revelam uma transparência estetizadora atravessada pela luz de uma identidade que tem na aparência a sua essência. O boi de Parintins seria o exemplo mais vibrante da conversão semiótica no processo cultural, isto é, uma tradução da tradição.

Palavras-chave: boi de Parintins, estética do vitral, conversão semiótica.

Abstract: In an allegorical language the author points out the concept from aesthetic of the stained glass to understand the cultural phenomenon of Amazonian, which manifestations reveal aesthetics transparence across from its identity that shows essence through apearence. The boi from Parintins would be the most vibrating example of semiology conversation into the cultural process, which means a translation of tradition.

Keywords: boi from Parintins, aesthetic of the stained glass, semiology conversion.

$\mathrm{V}$ enho analisando a expressão cultural de identidade, transfigurada pela dominância do estético (Paes Loureiro, 2000b), segundo o conceito compreensivo da estética do vitral. Creio que é um dos caminhos para sentir e interpretar essa dimensão plurissignificante da expressão simbólica do sentimento coletivo seja nacional, seja de grupos constituidores de comunidades emocionais. Essas manifestações, que importam em um conjunto de rica plasticidade, aparentemente efêmeras, ligadas a movimentos coletivos, objetivam e socializam o sentimento estetizador e identitário de um povo. Percebo, especialmente na Amazônia, cuja cultura gira em torno do eixo da

*Doutor em Sociologia da Cultura, poeta, professor da Universidade Federal do Pará e presidente do Instituto de Artes do Pará. 
poética do imaginário (Paes Loureiro, 2000a), a revelação dessa transparência estetizadora da cultura atravessada pela luz de uma identidade que tem também na aparência a sua essência.

Devo acentuar que as observações, a seguir desenvolvidas, seguirão uma linha de reflexão alegórica ou reflexão alegorizante, deixando o espírito em liberdade e enriquecido pelo devaneio.

O sentimento socialmente compartilhado e recriado em símbolos expressivos de forma estetizada, valoriza a expressão sensível e coletiva do estar em união. Funcionam essas expressões, como o Boi-de-Parintins (Paes Loureiro, 2000a), o Carnaval, a Época Junina, o Boi-Tinga, ${ }^{1}$ a Marujada, ${ }^{2}$ o Pássaro Junino, ${ }^{3}$ por exemplo, na forma de um vitral estético atravessado pela luz de um sentimento de identidade regional ou nacional. A atenção é atraída, basicamente, para a exterioridade do signo cênico, que se revela organizado na estrutura fragmentária mas pregnante do vitral, onde o uno está sustentado pela diversidade.

Também, como nos vitrais artísticos, esses vitrais da nacionalidade estão muito ligados a um sentido espiritual elevado (neste caso, o espírito da identidade) que originaliza a criação coletiva e, aparentemente, espontânea. É uma forma ampla de comunicação do sentimento simbolizado e no reconhecimento do "estar junto", como se, através da beleza, uma submersa mensagem de identificação passasse ligando as pessoas, banhando, no caso regional, como as águas de um rio, a várzea fértil, a alma amazônica.

O que esse conjunto de manifestações cênicas glorifica são valores de uma nacionalidade ou regionalidade individuada, efervescente, amorosa de uma alma comum, sinal de orgulho, refúgio da confiança. "Mais do que "estar junto’ é a intuição de um 'ser junto', ser um corpo só, um corpo místico comunitário, talvez” (Paes Loureiro, 1999). Percebemos nesses conjuntos da visualidade popular - seja nas feiras, seja na arte "naif”, seja nos estádios de esportes, seja nas praias, seja no carnaval -, de um lado, a pregnância colorida como um verdadeiro painel de arte pública (conceito que será desenvolvido na segunda parte deste ensaio); de outro, a significação nacionalizante (ou regionalizante) de sentido identitário, que atravessa o conjunto cromático.

Há, sem dúvida, uma unidade nessa diversidade que alimenta tantos vitrais estéticos da identidade brasileira ou regional. O Brasil é uma nação constituída por nações, por uma infinidade de relações solidárias. Há um trans- 
bordamento afetivo, uma ostentação emocional, uma envergadura passional que instrui as relações entre os homens. A mestiçagem, a mobilidade social, a plasticidade do conjunto étnico contribuem para uma necessidade espontânea de se reconhecerem como unidade. É quando o sentido do "religare", do "être ensemble" explode em festa. Abrem-se os espaços à criação configurante desses vitrais da nacionalidade e da identidade, pela combinação formadora desses vitrais estetizados da cultura. São espaços, como o Boi-deParintins, o Carnaval, o Pássaro Junino, o Boi-Tinga, a Paixão de Nova Jerusalém, espaços privilegiados de reunião das diferenças e, por isso mesmo, ideais para que se manifeste a força do "religare", do "être ensemble”, do ser em unidade, que essas composições cênicas coletivas possam revelar.

Na Amazônia também, como em todo o Brasil, o cidadão se expressa essencialmente pela emoção. A racionalidade tem lugar adquirido, mas não é sua dominante. O sentimento é a sua razão, e a lógica articula-se através da aparência reveladora de sentido e não de um cauteloso processo intelectualizador. Não racionaliza. Exprime-se. Quer “ser” como uma forma de “estar”. Mostrar-se. Ser para o outro. Provocar o reconhecimento. No campo temático do qual estamos tratando, quer exibir um sentimento de nacionalidade ou de identidade para o outro, por via emotiva, na expressão simbólica de uma esteticidade de formas e cores. É, portanto, uma identidade dialogal e de apelo muito apropriado à expressão estética. Uma força de expressão. Um gesto. Teatraliza cromaticamente a sua identidade nacional ou regional, sua identidade assumida em símbolos, em emblemas.

Não é uma identidade sob clausuras éticas ou morais. É uma identidade em liberação estética. A lógica contrapõe o instinto, a intuição. Substitui o concreto pela metáfora. Ao invés de teorizações e conflitos doutrinários, o impulso criador. Ao pensamento normatizado contrapõe o cotidiano à história, à cultura, estetizados. Ao dogmático, a sensação e o sentimento. O imaginário adquire estatuto de realidade. Curte o entusiasmo. Faz do maravilhamento uma condição cotidiana de existência. Revela uma sociedade que se encanta de si mesma. Uma identidade dionisíaca e barroca vivida plasticamente de forma coletiva, extravasada. Uma identidade que se encontra na festa e não na guerra. Uma identidade carnal, orgiástica, apropriada a uma seriedade onde a mestiçagem se legitima pela emoção e sensualidade. De certa maneira uma identidade assumida esteticamente por uma espontaneidade não-formal. Na visibilização cromática de sua alma, ela, mais do 
que mérito ou conquista, significa festa. Celebração identificadora de uma comunidade de gosto.

Todos sabemos que o fenômeno estético tem como uma de suas possibilidades sociais esse caráter de religação, de formar comunidades emocionais envolvidas pelo mesmo fenômeno. Temos um grande exemplo disso no Pará, do ponto de vista mágico-religioso - o Círio de Nazaré. Da perspectiva predominantemente estética, temos outros fenômenos. Entre eles destacam-se o Pássaro Junino e o Boi-Tinga. No Amazonas, objeto motivador desta análise, o Boi-de-Parintins. Uma das peculiaridades que o tornam um evento estético é o privilegiamento de sua forma e a atração que a contemplação de sua modalidade de expressão provoca. A condição adquirida de signo autônomo e auto-expressivo.

Sabemos que a relação estética é uma relação de caráter sensível e de presença diante do objeto e, por isso mesmo, faz com que a essência das coisas se manifeste através de sua aparência. Hegel afirmou que temos nela, pela aparência, a expressão de um momento essencial da essência. Esse fenômeno se manifesta no Boi-de-Parintins, no Amazonas e no Boi-Tinga, no Pará, por exemplo. Dentro desse universo dos vitrais da identidade já preludiada na primeira parte deste estudo, passo a acentuar nessas manifestações estéticas da cultura, uma outra dimensão conceitual, a ser desenvolvida a partir deste ponto como um fator de Arte Pública, privilegiando a relação estética e a forma sobre a qual recai a contemplação.

Durante muito tempo o Boi-Tinga, no Pará, foi combatido por ser considerado a deterioração do boi tradicional, argumento tão inconsistente para defender a idéia de que as atividades da cultura popular fiquem petrificadas no passado, como se fossem frutos de um acaso e não da criatividade do homem inserido em seu contexto histórico, social e cultural. Mas esse boi de máscara pioneiro se impôs desde São Caetano de Odivelas. Noto também que toda forma de tradução assusta, porque, na verdade, temos uma tradição do uno, da racionalidade do uno, daquilo que é único. Tudo aquilo que se torna múltiplo acaba sendo, de certa maneira, punido. O grande exemplo é a Torre de Babel: a multiplicação das línguas foi uma punição pela quebra do uno. Na Amazônia há um outro exemplo, a língua geral: para bloquearem a comunicação entre as nações indígenas - cada uma das quais tinha na língua e na linguagem que utilizava as básicas expressões de sua cultura - os jesuítas e os catequistas criaram a língua geral. Ou seja, do múltiplo criaram o uno, para, através dele, terem o controle da informação, da comunicação, 
da relação verbal e do poder com as tribos na região. De certo modo percebese a tendência de buscar o uno e de recear a multiplicidade e a plurivalência das coisas.

Pode-se ver que toda tradução é uma provocação da plurivalência. Penso até que toda tradução é uma forma de androgenia e acaba criando uma dupla sexualidade para o passado e para o futuro, e por isso abre a unidade do ser. Obviamente, porém, uma tradução realmente fascina mais pelo intraduzível do que propriamente pelo traduzido. Mas, toda obra de arte não fascina mais pelo indizível do que propriamente pelo que diz? A tradução tem esse condão: todo aquele que se volta para traduzir volta-se para o que é intraduzível, mas o segredo da tradução é que, ao traduzir, resguarda o intraduzível, ficando este como um vetor para novas traduções, segundo o processo da "gestação consumatória”. O que é a gestação consumatória? É um provocar ininterrupto do novo através daquilo que está sendo. Portanto, eu creio que todos nós estamos voltados, como numa insurreição, para o desejo de tradução e, assim, procedemos a cada momento. Até porque precisamos incorporar as coisas à nossa paisagem cultural, e nessa paisagem cultural as transformamos em nossas almas e, evidentemente, temos aí um processo de conversão. Um processo que denomino, em Cultura Amazônica - uma poética do imaginário (2000a), de “conservação semiótica”.

Nessa reflexão, eu destaco um outro exemplo da região amazônica: o Boi-deParintins que é a convergência temática deste estudo. Ele é o exemplo mais conhecido e mais vibrante do que seria uma tradução ou de uma conversão semiótica no processo cultural na região.

O Boi-de-Parintins incorporou os elementos da estética do carnaval. É um boi que chamo de carnavalizado e que, ao mesmo tempo, assumiu o processo que, na literatura, depois de Oswald de Andrade, passou a se chamar de antropofagia. Trata-se, portanto, de uma manifestação de arte pública antropofágica carnavalizada. Antropofágica na medida em que se alimentou e se alimenta das influências do carnaval e da mídia. Carnavalizada, porque se exibe portando aspectos semiológicos, simbólicos e plásticos que são próprios do carnaval. Mário de Andrade, que viajou até nossa região no começo do século, disse, passando pela frente de Parintins, que era extraordinário ver como tudo se enchia de entes, de deuses, de seres indescritíveis por detrás. Sobretudo se, no longe em frente, havia uma volta de rio. Ele soube captar muito bem essa qualidade de infinitude, de sobrenaturalidade que a paisagem dos rios amazônicos contêm. E é claro que isso está 
incorporado na paisagem cultural de cada habitante da região. Não são apenas as pessoas das metrópoles que têm uma paisagem cultural incorporada em sua alma, mas o caboclo da beira do rio, o trabalhador do campo e o homem da floresta também. Evidentemente, as pessoas de Parintins incorporaram na paisagem de sua alma esse desejo de infinitude. Daí o boi ter assumido grandiosidade, como se fosse uma prosopopéia, isto é, algo imenso, maior aparentemente do que a própria cidade. Algo que é desmesuradamente maior do que si mesmo.

O enredo tradicional do boi-bumbá pode ser enunciado da seguinte forma: o fazendeiro tem um boi e a Catirina deseja esse boi; o marido de Catirina, o Pai Francisco, resolve buscar o boi ou então matá-lo para que ela possa comê-lo, mas apenas fere o boi; ele é descoberto, o patrão tenta puni-lo; a partir daí, o Pai Francisco é obrigado a tomar todas as providências para fazer o boi ressuscitar; vai buscar o médico, que nunca o ressuscita e é sempre o pajé que, no final, o consegue. Esse enredo possui a circularidade que o aproxima da narrativa mítica: o boi tradicional se exibe na arena, gira em torno da plasticidade de seus elementos cênicos; não apresenta uma continuidade horizontal, mas uma circularidade que aprofunda a história através das toadas cantadas de improviso pelo dono do boi, o patrão.

O Boi-de-Parintins, por sua vez, transformou a circularidade mítica numa continuidade discursiva e narrativa moderna dos grandes espetáculos, especificamente do grande espetáculo que é o carnaval e, por isso, desfila ao longo de uma platéia fascinada por ele. Todo mundo sabe o que vai acontecer, de modo que a estrutura dramática do boi não é o interesse pelo que vai acontecer, mas como vai acontecer aquilo que se sabe que vai acontecer. $\mathrm{O}$ genial é que, à semelhança dos entreatos da comédia dell'arte, do teatro tradicional ou dos carros alegóricos nos desfiles de carnaval, foram criados personagens, originais carros alegóricos, grupos de alegorias, que vão se interpolando às cenas que narram essa pequena história do boi. Como cada desfile de boi dura três horas, é claro que, para manter o interesse de uma platéia de mais de 35 mil pessoas, é necessário recheá-lo de novidades, de atrações, de brilho, de surpresas, para que a platéia possa manter-se acompanhando a apresentação.

Temos, portanto, que o Boi-de-Parintins é um boi antropofágico, que se alimenta da influência de outras expressões culturais, incorporando-as à sua substância, e ao mesmo tempo carnavalizado, porque juntou a tradição do boi-bumbá à forma de exibição destinada ao grande público para o qual se 
propõe. Muitas expressões da arte popular repetem uma mesma forma de apresentação porque não têm acesso a novos materiais ou técnicas, por motivos de ordem econômico-social ou de informação. Mas o Boi-deParintins, quando teve acesso a novas técnicas, a modernos equipamentos de som, a um espaço enorme para se exibir, à grandiosidade do espaço cênico, evidentemente transformou-se para se ajustar a essa nova possibilidade de expressão. Um dos antigos organizadores desse boi me disse: "Olha, quando começamos esse boi, iluminávamos a cena com lamparina, que é esse pequeno farolzinho que você acende e fica ali tocado pelo vento. Era uma plataforma pequena, pouca gente. À medida que o espaço foi crescendo, a iluminação melhorou e surgiram novas possibilidades, fomos criando e estabelecendo novas formas de expressão de acordo com tudo isso”. As palavras não foram bem essas e nessa ordem, mas traduzem o que ele pretendia dizerme. Isso significa que, na verdade, temos uma arte pública extraordinária, agora se expandindo em comunicação com outras culturas, e que, através de materiais e técnicas, a população ribeirinha teve a possibilidade de ampliar largamente a sua criatividade.

\section{Pontos a destacar, em resumo:}

1) O que significa a carnavalização do Boi-de-Parintins? A incorporação de signos considerados inerentes às escolas de samba e ao desfile carnavalesco na estrutura desse bumbá. Por exemplo: o caráter do desfile, a relação com os espectadores, a monumentalidade, a presença de figuras de destaque, o uso de carros alegóricos, a função da toada usada com a mesma função do samba-enredo, a incorporação de fantasias como vestimentas, a intensificação do ritmo da bateria. Todos esses elementos municiam com argumentos tanto os tradicionalistas como os evolucionistas. A sócio-antropologia tem nisso um farto material a seu dispor. A minha opção nessas reflexões vem sendo a da simetria estético-sociológica. Nessa linha, cabe refletir sobre o efeito artístico que esses acréscimos, resultantes da antropofagia cultural, provocaram nesse trajeto antropológico, motivador de uma conversão semiótica do Caprichoso e do Garantido, em uma nova modalidade de boibumbá: o Boi-de-Parintins. Um rico e vivo processo antropofágico-carnavalizador na cultura amazônica.

2) O que significa o significado do Boi-de-Parintins como processo de tradução da tradição? Porque ele é a busca do novo sem a negação do antigo. Ao contrário, reafirma o antigo, na medida em que esse novo seria impossível de ser sem a existência do modelo anterior. Sua dupla sexualidade, sua 
androginia decorre de fecundar o passado na medida em que se deixa fecundar pelo futuro. Sem temer o presente é uma realização voltada para o futuro. Experimenta uma abertura do ser como unidade para configurar-se múltiplo. Claro que o que fascina nesse processo de tradução da tradição que o Boi-de-Parintins representa é a presença do intraduzível no que foi traduzido. Isso é que faz com que, mesmo diferente, o Boi-de-Parintins seja também um auto do boi. Pelo traduzido o Boi-de-Parintins é um boi carnavalizado e antropológico. Pelo intraduzível é que ele é o perene auto do boi junino, com seu "ethos" popular revelador das raízes simbólicas da cultura amazônica. O caboclo amazônico como produtor de vanguardas artísticas e de conhecimento.

3) O que significa ser o boi de Parintins um dos componentes do que eu chamo de vitrais do Brasil? É que ele representa essa forma exterior de expressão regional-nacional, efervescência de uma identidade submersa, um sentimento de necessidade espiritual do estar-juntos como região-nação coincidente com a forma de reflexão alegórica que estamos seguindo segundo a estética do vitral (concreto e imaginário), se considerarmos que a reunião dessas danças, alegorias, vestimentas, músicas, ritmos constitui a expressão cênica de uma esteticidade, de uma dramaturgia das paixões atravessadas pela luz de identidade. No espaço cênico-dramático do Boi-deParintins - assim como um estádio de futebol, nas feiras culturais, festas, visualidades populares -, há manifestações cromáticas-dramáticas-poéticas dos signos nacionais de expressão simbólica da cultura (no caso, amazônica-brasileira), podendo ser visto como uma verdadeira instalação pública (conjugando-se o conceito de instalação e arte pública). Essas instalações públicas correspondentes a um vitral da identidade, quando a criatividade organiza painéis cromáticos-dramáticos-poéticos pelos quais transparece a luz de um sentimento de amazonicidade (ou brasilidade), representam um gesto espontâneo, mas não gratuito. Um gesto identitário formalizado como jogo, com graça e invenção.

4) O que significa ser o boi de Parintins um exemplo de arte pública brasileira? É que essa manifestação cênica, situação em que o Brasil olha-se no espelho brasileiro, tem a oportunidade comunitária de se reconhecer nesse espelho cultural. É uma criação coletiva que nasce para ser coletivizada. Destina-se a uma situação pública, aberta, convivial, reveladora de um acréscimo à paisagem cultural através de um novo componente acrescentado à paisagem geográfica. Não tem a duração visível de um monumento escultórico ou arquitetônico na paisagem geográfica. Permanece, no entanto, 
na paisagem cultural, como uma forma de encantaria capaz de tornar-se visível a cada época junina anual. É como uma forma de epifania jorrando da paisagem cultura na paisagem geográfica, num momento de brilho, efervescência, delírio. Até poderíamos alegoricamente (que é o modo de interpretação que desenvolvo), numa aproximação comparativa com o mito da boiúna, afirmar que o ritual cênico, recolhido ou submerso na paisagem cultural, brota na paisagem geográfica do cotidiano, em uma outra forma de encantamento.

5) O que significa o boi de Parintins como um exemplo de conversão semiótica? A conversão semiótica (conceito que proponho em Cultura Amazônica - uma poética do imaginário) significa o quiasmo de mudança de qualidade simbólica em uma relação cultural, no momento em que ocorre essa transfiguração ou tradução. Pode-se observar esse fenômeno, por exemplo, tanto na criação artística, como no trajeto antropológico ou, mesmo, no processo da anomia. No boi de Parintins prevalece o sentido de libertação do imaginário do caboclo numa forma do presente. Um imaginário não mais apenas fecundado pela imaginação ribeirinha no isolamento lendárico, mas com a observação agitada pela televisão, vídeo, revistas policrômicas, reportagens. Prevalece o sentido cênico do boi agora convertido em espetáculo. Mas a expressão cênica vem enriquecida pelas novas informações da era das comunicações. Como nos ciclos artísticos, trata-se do novo convivendo historicamente com o antigo. Produto de um trajeto antropológico (G. Durand) coletivo, o boi de Parintins afirma a criatividade de uma comunidade amazônica e reverte o processo de imitação ou de reflexo regional pela criação de modelos novos geradores de influências. Não é uma expressão simbólica da cultura junina para se ver competitivamente com o boi-bumbá, mas convivendo na condição distintiva de sua individualidade.

\section{Notas}

1 - Boi de máscaras, do município de São Caetano de Odivelas, no Pará. Seu enredo é pura manifestação coreográfica e musical.

2 - Celebração a São Benedito, em Bragança, Pará. Praticada há mais de 200 anos, tem uma acentuada dimensão estética na dança e na visualidade.

3 - Teatro popular musicado criado no Pará.

\section{Referências bibliográficas}

BACHELARD, Gaston (1960). La poétique da la rêverie. Paris: Quadridge/PUF. 
DURAND, Gilbert (1994). Les structures anthropologiques de l'imaginaire. Paris: Dunod.

FONTES, Joaquim Brasil (1991). Eros, tecelão de Mitus. São Paulo: Estação Liberdade.

MAFFESOLI, Michel (1986). O paradigma estético. Revista do SPHAN, $\mathrm{n}^{\mathrm{o}}$ 21.

MUKAROVSKY, Jean (1981). Escritos sobre Estética e Semiótica da Arte. Lisboa: Estampa.

PAES LOUREIRO, João de Jesus (2000a). Cultura amazônica - uma poética do imaginário. $2^{\underline{a}}$ ed. São Paulo: Escrituras Editora. . (2000b). Vitrais do Brasil. In: O Brasil na visualidade popular. Belo Horizonte: Museu de Arte de Pampulha. . (1999). Arte pública como conversão semiótica. In: Arte pública. São Paulo: SESC. 